ARTIGO

\title{
POLÍTICA DE INDEXAÇÃO EM ARQUIVOS DE INSTITUIÇõES DE SAÚDEi
}

\author{
INDEXING POLICY IN ARCHIVES OF HEALTH INSTITUTIONS
}

${ }^{1}$ Doutora em Ciências da Comunicação pela Universidade de São Paulo (USP).

\section{E-mail: mariangela.fujita@unesp.br}

${ }^{2}$ Doutora em História Social pela Universidade de São Paulo (USP).

\section{E-mail: sonia.troitino@unesp.br}

\section{ACESSO ABERTO}

Copyright: Esta obra está licenciada com uma Licença Creative Commons Atribuição 4.0 Internacional. $(\boldsymbol{c c}) \mathbf{B Y}$

Conflito de interesses: As autoras declaram que não há conflito de interesses.

Financiamento: Não há.

Declaração de Disponibilidade dos dados: Todos os dados relevantes estão disponíveis neste artigo.

Recebido em: 20/09/2018.

Revisado em: 01/10/2018.

Aceito em: 10/10/2018.

\section{Como citar este artigo:}

FUJITA, Mariângela Lopes; TROITIÑO, Sonia. Política de indexação em instituição de saúde. Informação em Pauta, Fortaleza, v. 3, número especial, p. 95-116, nov. 2018. DOI:

https: //doi.org/10.32810/25253468.ip.v3iEspecial.2018.39719.95-116.

\section{RESUMO}

A indexação é uma operação que, para ser bemsucedida na representação e na recuperação,

\author{
Mariângela Spotti Lopes Fujita ${ }^{1}$ \\ Sonia Maria Troitiño Rodriguez ${ }^{2}$
}

depende da definição de uma política que para sua elaboração e implementação precisa avaliar o contexto da instituição mediante requisitos para a definição de elementos e variáveis influentes tanto na indexação quanto na recuperação. Entre esses elementos está o vocabulário controlado e o processo de indexação que propiciarão especificidade e/ou exaustividade. Entretanto, antes de tudo, é necessário o debate e reflexão sobre a aplicabilidade da indexação e da política de indexação na gestão documental em âmbito arquivístico de instituições de saúde. Este trabalho, de característica ensaística, propõe uma abordagem sobre as relações existentes entre as políticas de gestão documental e de indexação com o objetivo de refletir sobre a aplicabilidade da elaboração e implementação da política de indexação no âmbito das instituições de saúde pública no Brasil. 0 desenvolvimento da proposta de política de indexação aplicada a arquivos de instituições de saúde revela inovação do ponto de vista sistêmico à rede nacional de saúde e a necessidade de desenvolvimento de metodologias de representação da informação dentro de uma política estabelecida em consonância com as necessidades de recuperação informacional da organização.

Palavras-chave: Política de indexação. Gestão documental. Arquivos. Instituições de saúde.

\section{ABSTRACT}

Indexing is an operation that, in order to be successful in representation and retrieval, depends on the definition of a policy that, for its elaboration and implementation, needs to assess the institution context through requirements for 
the definition of influential elements and variables in both indexing and retrieval. Among these elements is the controlled vocabulary and the indexing process that will provide specificity and / or exaustivity. However, above all, it is necessary to debate and reflect on the applicability of indexing and indexing policy in records management in the archival area of health institutions. This work, which is an essay feature, proposes an approach on the relationship between records management and indexing policies, with the objective of reflecting on the applicability of indexing policy formulation and implementation within public health institutions in Brazil. The development of the proposed indexing policy applied to the archives of health institutions reveals innovation to the national health network and the need to develop methodologies of information representation within a policy established in line with the needs of informational retrieval of the organization.

Keywords: Indexing policy. Records management. Archives. Health Institutions.

\section{INTRODUÇÃo}

Debater sobre Gestão Documental e Política de Indexação em Instituições de Saúde é um tema de grande envergadura. 0 desafio inicial parte da própria proposta colocada, tanto por sua amplitude e complexidade, quanto pelo diversificado leque de possibilidades conceituais existente.

Com características ensaísticas, este artigo busca refletir sobre a aplicabilidade de uma metodologia específica para a indexação de documentos no âmbito das instituições de saúde pública no Brasil. Mais do que falta recursos tecnológicos para a gestão e tratamento documental da área da Saúde, o que se percebe, em termos gerais, é falta de precisão na definição sobre quais são os documentos sobre saúde produzidos por suas instituições, a partir dos processos de trabalho que lhes correspondem, sejam relativos a atividades-fim ou a atividades-meio. Documentos estes que são efetivamente os reais portadores de informações.

Essa definição passa obrigatoriamente pelo próprio entendimento sobre o que é o documento arquivístico e sobre o que se deve preservar, seja com finalidade de gestão administrativa de informações, seja com função memorialística de atos institucionais. É uma tomada de decisão que afeta diretamente sobre o que se pode expurgar ou não, sem que haja ocorrência de prejuízos para o indivíduo e para a sociedade, como um todo. Contudo, é compreensível a pergunta que surge a partir da seguinte constatação: a gestão documental e a indexação podem ser consideradas faces distintas de uma mesma moeda (sistema de informação arquivística). À medida que a primeira se ocupa do tratamento integral do registro, enquanto documento de arquivo, acompanhando 
integralmente o seu ciclo vital e garantindo preservação e acesso contextualizado, a segunda se debruça sobre o conteúdo do documento, de modo a sistematizar informações e facilitar sua recuperação e uso. Nesse sentido, gestão documental e indexação possuem uma relação indissociável? Considerando constituírem elementos simultâneos de composição de um sistema de informação arquivística, cunhados em faces opostas, raramente são concebidos como procedimentos complementares do tratamento da informação em arquivos.

No âmbito dos arquivos, de acordo com Sigmond (1991), grande parte das vezes os arquivistas argumentam que é preciso muito tempo para a indexação de documentos de arquivo; que essa é uma escolha subjetiva para decidir quais assuntos devem ser inseridos e, portanto, tais listas são imprecisas e improdutivas. Diante do grande volume de documentos que abarrotam os arquivos, é compreensível a preocupação dos profissionais que atuam em arquivos com o tempo despendido para cada uma das etapas de trabalho de organização documental. Contudo, o tempo demandado, assim como o argumento de "imprecisão e improdutividade", são obstáculos originários ou acentuados pela falta de rigor metodológico no ato de se indexar. 0 que deve ser considerado neste, e em todos os outros critérios adotados para a recuperação da informação, é a relação custo-benefício para o usuário ou pesquisador.

Barbadillo Alonso (2007) defende que a indexação pode colaborar com o processo de classificação arquivística da documentação ao ser empregado no nível hierárquico série, evitando o desmembramento desta em subséries, normalmente criadas com parâmetros temáticos. Evita-se, assim, sobrecarregar o plano de classificação do fundo, sob risco de perda de sua coerência interna, ao substituir o critério tipológico pelo temático para a classificação de documentos. Dessa forma, desvios classificatórios e o surgimento de unidades documentais de caráter misto são evitados, aumentando o controle sobre a produção documental. Contudo, classificação e indexação não devem nunca ser confundidas. São processos de natureza distinta, com objetivos e resultados diferentes. Entretanto, quando bem aplicados simultaneamente, trazem inúmeros benefícios aos usuários da informação.

Por sua vez, Cruz Mundet (2008) considera o sistema de indexação como um recurso interessante a ser aplicado na descrição arquivística de documentos, sem o prejuízo de substituição ou adulteração da classificação arquivística.

Segundo o autor, o processo de indexação em arquivos compreende três etapas: 
1. Examen del documento y determinación de su contenido, prestando atención a los siguientes elementos: emisor (actor), receptor, canal (procedimientos), mensaje (asunto) y contexto, siguiendo a Jakobson en su teoría del acto comunicativo (JAKOBSON, 1974).

2. Identificación y selección de los conceptos principales, extraídos del documento mediante análisis intelectual y transformados posteriormente en términos de indización.

3. Selección de términos de indización que expresen los conceptos de los documentos, bien mediante términos contenidos en ellos o a través de otros que elijamos y sean representativos. (CRUZ MUNDET, 2008, p. 219)

Para isso, ainda segundo Cruz Mundet (2008), as linguagens de indexação utilizadas para refletir o conteúdo documental podem ser: 1) linguagens codificadas (numéricas ou alfanuméricas), a semelhança das utilizadas na classificação; 2) linguagens livres; 3) linguagens controladas; e/ou 4) linguagem humana. Entre estas, as mais recorrentemente utilizadas são as linguagens livres, construídas a partir da leitura e interpretação dos próprios objetos a serem representados, os documentos; e as linguagens controladas, elaboradas a partir de estudos temáticos sobre os fundos de arquivo e demanda de seus usuários.

Tradicionalmente, o processo de indexação em arquivos é aplicado na etapa de descrição documental sobre documentos da terceira fase do ciclo vital, o arquivo permanente. Entretanto, Troitiño; Fujita; Neves (2016) trazem um elemento novo ao considerarem a aplicação da indexação na fase inicial do ciclo vital do documento, mais precisamente, no momento de seu protocolo. Argumentam que, no processo de gestão documental, a indexação assume função de destaque devido ao papel que cumpre ao representar a informação, auxiliando na recuperação de documentos. Por outro lado, também atua diretamente na racionalização do sistema de organização documental ao colaborar com a aplicação do plano de classificação, sem que este acarrete na ocultação de conteúdos de ordem temática. Assim sendo, consideram que o nível classificatório adequado à aplicação da indexação é o do documento, por este apresentar uma estrutura textual propícia para a identificação de conceitos úteis ao gerenciamento de informações e recuperação com fins de acesso. Assim, o momento propício para a aplicação da indexação em sistemas de gestão arquivística de documentos se dá durante o protocolar da unidade documental. Visão que complementa a de Barnand Azamorrutia (2002) ao afirmar que o registro e descrição de um documento de arquivo servem para homologar sistemas de acesso e recuperação, além de facilitar seu controle, localização física e elaboração de instrumentos de controle e acesso à informação. 
No esteio dessas constatações, o que propomos neste trabalho é uma nova abordagem sobre as relações existentes entre as políticas de gestão documental e de indexação. Abordagem que considere uma perspectiva integrada entre as metodologias e práticas efetivas dos processos de trabalho relativos à gestão documental e à indexação em sistemas arquivísticos de informação. Para isso, primeiramente, se faz necessário tecer algumas considerações preliminares sobre os preceitos de ambos os campos, a fim de verificar aproximações e distanciamentos conceituais existentes entre ambos, antes de entrar propriamente na questão Política de Indexação. Procedimento este que permite elucidar determinados pontos a fim de perceber as reais conexões possíveis entre gestão documental e indexação.

\title{
2 ARQUIVOLOGIA E ARQUIVOS
}

A arquivista espanhola Martín-Pozuelo Campillos, ao tratar sobre a institucionalização como fenômeno social, comenta que

\begin{abstract}
Al mismo tiempo se pude asegurar que toda actividad humana debe ser definida como hábito o conjunto de hábitos que con el transcurrir del tiempo nos proporcionan el material suficiente para confeccionar una memoria colectiva. En su carácter repetitivo toda actividad humana anula la necesidad de volver a conceptualizar o definir cada situación de nuevo. Una gran variedad de situaciones nos alertan de las que probablemente mañana volverán a repetirse; mañana esa gran variedad de situaciones se verá cuantitativamente incrementada. El hombre, con su capacidad de abstracción, observa ese material y lo tipifica. Cuando esa tipificación responde a layes de reciprocidad entre actividad habitualizadas y sujetos habitualizadores, estamos en presencia de la institucionalización (MARTÍN-POZUELO CAMPILLOS, 1996 p. 65).
\end{abstract}

É a institucionalização a base formadora de qualquer entidade jurídica e, por sua vez, a institucionalização de documentos a base formadora do arquivo da entidade. Revela-se, então, a essência do arquivo e de seus componentes: "a necessidade que a Instituição tem do arquivo emana diretamente da necessidade de justificar sua própria existência" (MARTÍN-POZUELO CAMPILLOS, 1996, p. 83). Nesse sentido, a instituição pode também ser entendida como elemento fundamental da gênesis de sua própria produção documental.

De modo sintético, o conjunto que conforma o arquivo não é nada além da reunião de documentos de uma mesma origem, produto de funções e atividades 
desempenhadas por determinada entidade (seja pública ou privada; seu titular, pessoa física ou jurídica). Assim, conhecer o sistema organizacional da entidade, identificando funções, atividades, rotinas e procedimentos, leva a compreensão dos mecanismos do sistema de registro e de acesso à informação e, consequentemente, à contextualização da produção documental e do próprio arquivo. Ainda que exista muitas acepções para o termo arquivo, aqui delimitaremos nossa reflexão à discussão sobre arquivos de instituições.

Segundo Heredia Herrera (2007), as instituições arquivísticas se reconhecem pelos documentos que custodiam e pelas funções que a partir deles se realizam. Isso nos leva a considerar que apesar de não ser possível falar em instituições ou documentos temáticos de arquivo, é possível considerar conteúdos informacionais passíveis de categorização temática. Isso porque a lógica da contextualização arquivística deve, obrigatoriamente, seguir o princípio da proveniência.

A proveniência remete a compreensão da origem comum das unidades documentais inter-relacionadas que formam um arquivo. Na qualidade de pilar da teoria arquivística, estabelece que os documento oriundos de uma instituição, organização ou indivíduo devem manter sua individualidade, não sendo misturados a conjuntos estranhos a sua proveniência. Dessa forma, não há o perigo de se incorrer em equívocos de interpretação de informações textuais e não textuais (TROITIÑO, 2017).

A maioria dos autores coincidem ao entender o princípio da proveniência com um duplo valor: 1) o de respeito à origem dos fundos; e 2) o de respeito às estruturas do fundo, individualmente, e a disposição dos documentos em seu interior (MARTÍNPOZUELO CAMPILLOS, 1996, p. 24). Enquanto o primeiro valor remete à preservação do conjunto orgânico de documentos de mesma origem, mantendo-os agrupados, sem mistura-los a documentos ou de outras proveniências, o segundo diz respeito a manutenção da coerência interna de um fundo, por meio do respeito à classificação arquivística e à ordem original atribuída pela organização burocrática da qual procede, espelhando a organização interna que lhe é própria.

Mello e Silva (2014, p. 11) constatou, durante a pesquisa que resultou em seu Glossário de espécie e tipos documentais em arquivos de laboratórios, que os arquivos oriundos de instituições de ciência e tecnologia não se diferenciam dos produzidos por qualquer outra área do conhecimento no que se refere ao tratamento documental e à teoria arquivística a serem empregados. 0 que pode variar e se tornar um diferenciador 
entre esses arquivos seria, na realidade, os tipos documentais produzidos ao longo do cumprimento das funções e atividades das instituições produtoras de documentos. Essa é uma constatação importante e reveladora pois evidencia que documentos são produto de atividade e não de tema. Porém, missão institucional se baliza em temas.

Desde logo, a existência de arquivos em uma instituição não garante a existência de sistema arquivístico. São ordens diferentes. Em instituições, a existência de arquivos é quase automática, posto que o regime burocrático que conduz administrações públicas e privadas se pauta no registro documental de seus atos. Onde há documentação orgânica relacionada, há arquivo. Contudo, um sistema arquivístico é algo mais complexo, que exige determinada estrutura e condições de existência que viabilizem a integração de diferentes arquivos, em distintas idades documentais. O grande fio condutor do sistema é, sem dúvida, a gestão documental.

Conforme a Lei Federal no 8159/1991, art. 3ํㅜ, “considera-se gestão de documentos o conjunto de procedimentos e operações técnicas referentes à sua produção, tramitação, uso, avaliação e arquivamento em fase corrente e intermediária, visando a sua eliminação ou recolhimento para guarda permanente" (BRASIL, 1991). Parte-se de uma perspectiva global do monitoramento da existência do documento, desde do momento de sua criação ao de destinação.

É sempre importante lembrar que a gestão arquivística de documentos compreende a responsabilidade dos órgãos produtores e das instituições arquivísticas que os custodia, a fim de assegurar que a documentação produzida se mantenha como o registro fiel das suas atividades e que os documentos definidos como de guarda permanente sejam devidamente recolhidos às instituições arquivísticas e preservados, Conselho Nacional de Arquivos-CONARQ (BRASIL, 2011). Esse é o objetivo. Todos os benefícios que se seguem - controle, racionalização administrativa, valor probatório, economia, cidadania, história, etc - emergem a partir desse zelo.

\section{PRODUÇÃO DOCUMENTAL, DOCUMENTOS E INDEXAÇÃO}

A produção documental de qualquer instituição é realizada pela necessidade do registro do conhecimento gerado durante o desenvolvimento natural de sua missão. 0 documento terá, assim, forma física e conteúdo específicos da produção documental da 
área de domínio da instituição que gerou o conhecimento. Tribunais produzem documentos específicos como, por exemplo, acórdãos; universidades produzem projetos e relatórios de pesquisa; escolas de ensino fundamental e médio produzem planos de ensino e apostilas; hospitais e ambulatórios produzem o prontuário do paciente; etc.

A documentação produzida é, então, organizada para ser, futuramente, acessada e recuperada por seus usuários com necessidades de informação, seja ela impressa em suporte físico ou eletrônica em suporte digital. No entanto, para que a recuperação aconteça, é preciso que a documentação tenha passado por processos de gestão documental para garantir sua preservação. É importante, sobretudo, destacar que o suporte digital dá visibilidade e disponibilidade aos documentos para acesso online onde seus usuários estiverem. Esta condição é, atualmente, bastante estratégica, porém, precisa atender requisitos específicos para sistemas informatizados de modo a garantir acesso e recuperação, como também, interoperabilidade entre os vários sistemas informatizados e compartilhar recursos informacionais padronizados, além de preservação digital.

A documentação em arquivos poderá ser recuperada por elementos de sua forma física e de conteúdo durante a descrição documental, tais como, produtor, procedência, identificação documental, autoria, datas ou palavras do título, ou por assunto que represente seu conteúdo. A representação do conteúdo por assuntos ou termos autorizados de um vocabulário controlado é realizada após análise documental que se realiza para fins de indexação.

A indexação é um processo de análise para identificação e seleção de conceitos significativos de conteúdos documentais que, extraídos do contexto documental, são representados por termos autorizados de um vocabulário controlado e passíveis de serem recuperados em estratégias de busca de usuários para acesso e localização documental.

Esta correspondência do uso do mesmo vocabulário pelo indexador durante a análise e representação documental e pelo usuário durante sua busca é uma grande vantagem em sistemas de recuperação da informação que precisa ser alertada a todos que trabalham com a gestão documental, principalmente, para aqueles sistemas em que é possível o auto arquivamento pelo autor. 0 vocabulário é um instrumento de representação da informação cuja escolha depende da (s) área (s) de conhecimento e do contexto institucional regido ou não por políticas públicas. 
Determinar quais conceitos representam o conteúdo documental, fora do seu contexto textual para futuros acessos por determinados usuários, especializados e/ou leigos e finalidades, tem método que é influenciado pelo contexto de gestão documental, dotado de infraestrutura física, tecnológica e de pessoas, e que se insere em um outro contexto maior de política institucional e de política pública.

Arquivos, principalmente, estão articulados a uma importante política de acesso à informação, regida pela Lei № 12.527 de 18 de novembro de 2011 (BRASIL, 2011). 0 arquivamento documental sem controle de vocabulário e sem definição de procedimentos de representação descritiva e temática da documentação gera problemas de recuperação. Por isso, é que existem instituições técnicas, profissionais e governamentais que, em um esforço de melhorar o compartilhamento e interoperabilidade entre sistemas e vocabulários, estabelecem normas, padrões e requisitos gerais e específicos para a organização e representação da informação. A Norma Internacional de Descrição Arquivística (ISAD(g)) e a Norma Internacional sobre os Registros de Autoridades de Arquivos relativos à Instituições, Pessoas e Famílias (ISAAR(cpf)), são normalizações importantes criadas para propiciar “[...]o acesso à informação de múltiplas perspectivas e o trabalho colaborativo entre diversas instituições de informação [...]” (LLANES PADRÓN; FUJITA, 2017). A partir dessas normas internacionais, outros países as utilizaram como fundamentação de suas normas nacionais, como é o caso do Brasil que criou a Norma Brasileira de Descrição Arquivística (NOBRADE).

A normalização da descrição arquivística abre possibilidades e vantagens importantes porque permite a representação da informação de modo uniforme, “[...] assegura a autenticidade, a acessibilidade, a disponibilidade e a apropriação de qualquer recurso de informação assim como a interoperabilidade entre sistemas de qualquer instituição." (LLANES PADRÓN; FUJITA, 2017). Com a determinação dos requisitos da descrição arquivística é possível a definição de metadados para registro dos itens informacionais necessários à representação descritiva e temática da documentação.

A indexação, como processo de representação temática, não é muito utilizada em arquivos, mas não é, também, utilizada em bibliotecas. Com longa tradição de normalização da descrição, as bibliotecas realizam a catalogação de assunto com normalizações que foram sendo aprimoradas ao longo do tempo assim como seus 
vocabulários controlados. A indexação tem fundamento histórico ligado ao controle bibliográfico que permitiu a produção de fontes bibliográficas especializadas em áreas do conhecimento dotadas de índices bibliográficos de autores, assuntos e títulos. Quando surgiu o uso de computadores, as bibliografias tiveram seus índices automatizados e, depois, com a internet as bibliografias se tornaram bases de dados especializadas disponíveis em portais e em sites na internet. Mas, o princípio da indexação permanece o mesmo e tem se aprimorado cada vez mais pela vantagem de ter a avaliação pela recuperação da informação de modo rápido e acessível. Essa avaliação tem propiciado comparações entre sistemas que indexam com e sem controle de vocabulário.

A indexação, por outro lado, como ato de construir índices, é prática bastante antiga no tratamento de documentos. Basta sabermos que em bibliotecas da antiguidade já existiam listas dos documentos ali armazenados. Entretanto, a partir do momento em que a ordenação dessas listas necessitou de uma organização por assunto, foram estabelecidas profundas mudanças na abordagem do ato mecânico de construir índices, ou seja, introduziu-se um processo de análise do conteúdo dos documentos com a finalidade de representação documentária.

A indexação, como processo de análise documental, passa a ser realizada mais intensamente desde o aumento de publicações periódicas e da literatura técnicocientífica de modo geral, que impulsionaram a necessidade de criação de mecanismos de controle bibliográfico em centros de documentação especializados. Assim, as bibliografias, como mecanismos de controle bibliográfico, surgiram fora do âmbito das bibliotecas tradicionais e apresentavam uma evolução nas técnicas de tratamento da informação, dando impulso teórico-prático, naquela ocasião, a uma nova área: a Documentação.

Com a evolução teórico-metodológica, em decorrência da necessidade de recuperação cada vez mais rápida, precisa e especializada por parte de Instituições informacionais, o tratamento da informação passou a contar com um aparato metodológico e instrumental mais diversificado e muito mais voltado para o contexto de cada documento. Ressalte-se que, a partir da evidência da Documentação como área científica na década de 60 e do surgimento dos serviços de informação em áreas especializadas, a indexação e a elaboração de resumos utilizados na elaboração dos serviços bibliográficos para recuperação de artigos de periódicos científicos ganharam 
espaço e notoriedade mantidos até hoje. A partir da evolução que determinou a importância do contexto do documento para a recuperação da informação, a área de indexação passa a incorporar os estudos dirigidos à compreensão do conteúdo dos textos a serem analisados. Com o crescimento dos serviços de indexação e resumo em todo mundo e a importância das bases de dados para o desenvolvimento científico e tecnológico, cada vez mais se buscava o aprimoramento teórico e metodológico da indexação com o objetivo de melhorar a recuperação por assuntos.

Considerando os avanços da indexação em relação à metodologia de representação do conteúdo documental e o uso de ferramentas de controle de vocabulário, bem como da avaliação da indexação, entendemos que seria possível sua aplicação em arquivos durante a descrição arquivística. Para isso, necessário se faz sua aplicação por meio da política de indexação que passaremos a explicar.

\section{POLÍTICA DE INDEXAÇÃO: PROPOSTA PARA ARQUIVOS DE INSTITUIÇõES DE SAÚDE}

O uso da indexação como processo de análise e representação da informação significa que o arquivo necessita oferecer recuperação da informação contida nos documentos conforme necessidade de informação formulada pelos usuários na estratégia de busca da base de dados. A indexação é uma operação que, para ser bemsucedida na representação e na recuperação, depende da definição de uma política que, antes de sua elaboração, precisa avaliar o contexto da instituição. Fujita e Gil Leiva (2014) destacam que em um sistema de informação a recuperação e a indexação são “[...] dois elementos que conformam as faces de uma mesma moeda e, portanto, indissociáveis um de outro. Entretanto, na hora de revisar, melhorar ou avaliar um sistema de informação, esses elementos podem ser analisados em separado." A indexação é aplicada para se obter bons resultados na recuperação, portanto, são indissociáveis e dependentes uma da outra. É uma operação intermediária e realiza uma mediação como forma de representação no que se refere ao documento prontuário do paciente, mas “[...] para que isso se efetive de fato, é preciso estar atento, pois, nesse caso, não se deve possibilitar entendimentos de uma lógica nebulosa, afinal a informação nesse âmbito deve ser precisa [...]" (PINTO; SILVA NETO, 2013). 
No entanto, para que essa correspondência aconteça, a adoção de uma política de indexação será norteadora de princípios e critérios que servirão de guia na tomada de decisões para otimização do serviço e da racionalização dos processos. A política de indexação se elabora e se implementa em conjunto e em consenso com os vários atores que dela participam: profissionais da informação, analistas de sistemas, gestores do arquivo e da instituição e, principalmente, usuários do sistema de informação. Para promover a participação ativa e integral de todos os atores interessados na política é importante adotar metodologia de pesquisa participante, como a pesquisa-ação integral. A pesquisa-ação é, segundo Thiollent (1998),

[...] um tipo de pesquisa social com base empírica que é concebida e realizada em estreita associação com uma ação ou com a resolução de um problema coletivo e no qual os pesquisadores e os participantes representativos da situação ou do problema estão envolvidos de modo cooperativo ou participativo. (THIOLLENT, 1998, p. 14).

Os procedimentos da metodologia da pesquisa-ação foram aplicados por Fujita (2017) em contexto de prática em rede de bibliotecas universitárias para vivenciar a ação de elaboração, implementação e avaliação da política de indexação como forma de melhor observar problemas e mudanças. Recomenda-se a metodologia de pesquisa-ação integral (MORIN, 2004) para a elaboração e implementação da política de indexação conjugado com o modelo bottom-up (Figura 1) para a implementação no qual o modelo de política elaborado não é definitivo e é modificável por aqueles que a implementam no dia-a-dia e de acordo com o seu contexto de prática (SECCHI, 2013).

Figura 1-Modelo bottom-up.

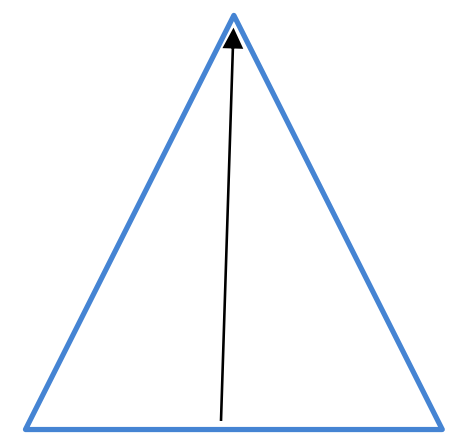

Fonte: Secchi, 2013, p. 61.

Assim, a política de indexação não se reduz apenas ao processo de indexação para representação e recuperação da informação, é mais amplo. Também, não é somente uma 
lista de procedimentos a serem seguidos. É um conjunto de decisões que esclarecem os interesses e objetivos de todos que participam e tenham necessidade de recuperação em um sistema de informação.

Com base na lógica de indissociabilidade entre indexação e recuperação se aplica a política de indexação cuja elaboração é baseada em dois planos: o vertical que representa as atividades de organização e representação da informação e o horizontal, onde o plano vertical se apoia, representa as atividades de gestão cujos requisitos definirão o tipo de política para cada instituição.

A definição da política de indexação de sistemas de informação institucionais está condicionada à existência dos seguintes requisitos referentes às atividades de gestão no plano horizontal (Figura 2): organização, clientela, recursos financeiros, materiais e humanos. 0 conjunto desses requisitos denotam que o funcionamento de um sistema de informação deve ser considerado na elaboração de uma política de indexação para verificar características e objetivos da organização, determinantes do tipo de serviço a ser oferecido; identificação dos usuários, para atendimento de suas necessidades de informação e recursos humanos, materiais e financeiros (CARNEIRO, 1985).

Figura 2- Plano horizontal da política de indexação.

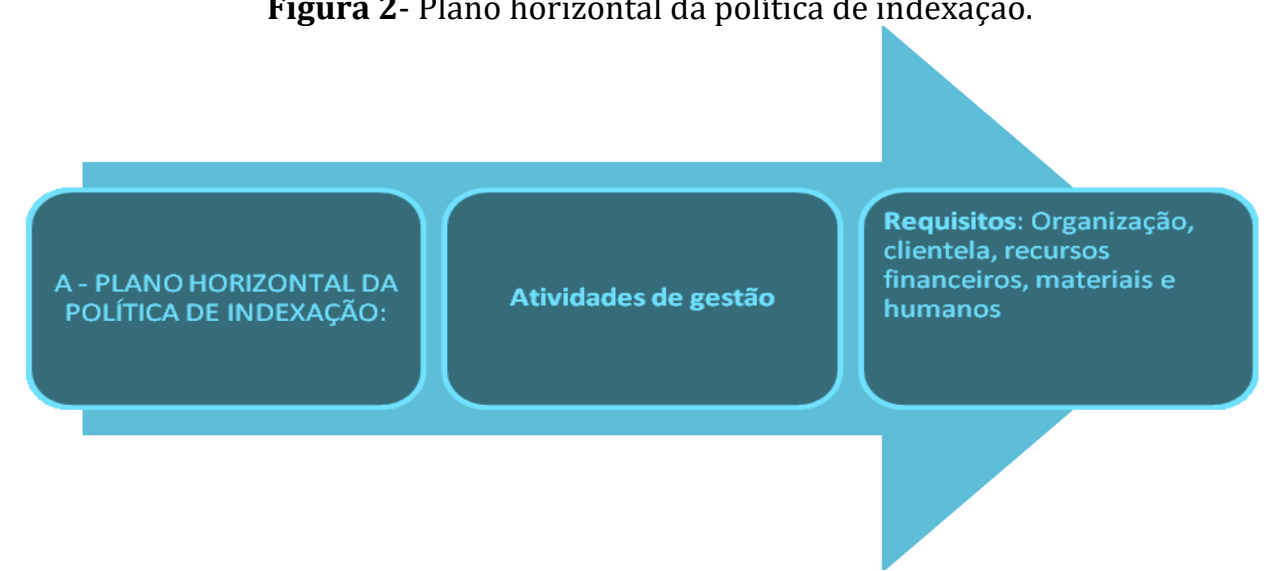

Fonte: Fujita, 2012, p. 24.

Dessa forma, cada requisito pode influenciar o plano vertical, como por exemplo, o usuário e suas áreas de domínio: especializados ou leigos, ou ambos. Se o usuário for especializado ou leigo irá influenciar a escolha de vocabulário controlado a ser utilizado para o processo de indexação e busca de informação. Se a comunidade usuária é especializada e leiga, o vocabulário terá que conter os dois tipos de vocabulário para que o uso seja combinado. Vocabulários controlados devem possuir sistema de equivalência 
entre termos sinônimos, homônimos e polissêmicos que prevê, sem problemas, vocabulários mistos. Quanto mais relações de equivalência existirem entre os termos, mais possibilidades de representação o vocabulário terá.

Por outro lado, o tipo de organização da instituição e seus recursos financeiros, materiais e humanos são importantes requisitos que definirão as condições de elaboração e implementação da política. Por exemplo, instituições de saúde, tais como hospitais estão inseridos em uma política pública importante que é a política de saúde do país e por isso precisam estudar seus recursos disponíveis para a elaboração da política de indexação de seus arquivos como, por exemplo: dentre as pessoas que trabalham para o sistema de saúde ou dentro dos hospitais quais poderiam trabalhar na elaboração e implementação da política de indexação?

A política pública de saúde tem suas diretrizes e marcos regulatórios próprios e principalmente aqueles que se referem aos princípios da Política Nacional de Informação e Informática em Saúde (PNIIS) (BRASIL, 2016) que dão conta de viabilizar o e-Gov e o e-Saúde que inclui o registro eletrônico em Saúde. Não restam dúvidas que a política nacional de saúde é uma grande e complexa rede de sistemas de informação que necessita, principalmente, de padronização de registros de saúde do cidadão e uma proposta de padronização do arquivamento eletrônico combinado com a indexação e uso de vocabulário controlado. Mas, cada instituição de saúde com arquivo precisa realizar a gestão documental e pode aliar a política de indexação para garantir a representação para recuperação da informação.

À respeito da padronização em torno da gestão e preservação documental de cada instituição de saúde, destaca-se o trabalho da Câmara Setorial de Arquivos de Instituições de Saúde, constituída pelo Conselho Nacional de Arquivos (CONARQ) do Ministério da Justiça, com a "[....] finalidade de realizar estudos; propor diretrizes e normas no que se refere à organização, à guarda, à preservação, à destinação e ao acesso de documentos integrantes de arquivos de instituições de saúde" (BRASIL, 2010). Essa Câmara do CONARQ elaborou as diretrizes para a avaliação de documentos em instituições de Saúde publicada como Resolução no 22 do CONARQ de 30 de julho de 2005. De acordo com Santos (2010), essa importante Resolução estimula as instituições a assumirem a gestão de seus acervos. Em 2007, o Conselho Federal de Medicina (CFM) lançou a Resolução CFM № 1821 de normas técnicas para digitalização e uso dos 
sistemas informatizados para a guarda e manuseio dos documentos dos prontuários dos pacientes (CONSELHO FEDERAL DE MEDICINA, 2007).

Esses e os demais requisitos que fornecem a visão do contexto da organização passam a fazer parte do conhecimento daquele que trabalha com a indexação e influência seu contexto de prática durante a indexação para representação documental. O eixo horizontal das atividades de gestão (Figura 3) em cada ambiente institucional será correlacionado com o eixo vertical das atividades de organização composta pelo que se denomina de elementos e variáveis da política de indexação.

Figura 3- Plano vertical da política de indexação.

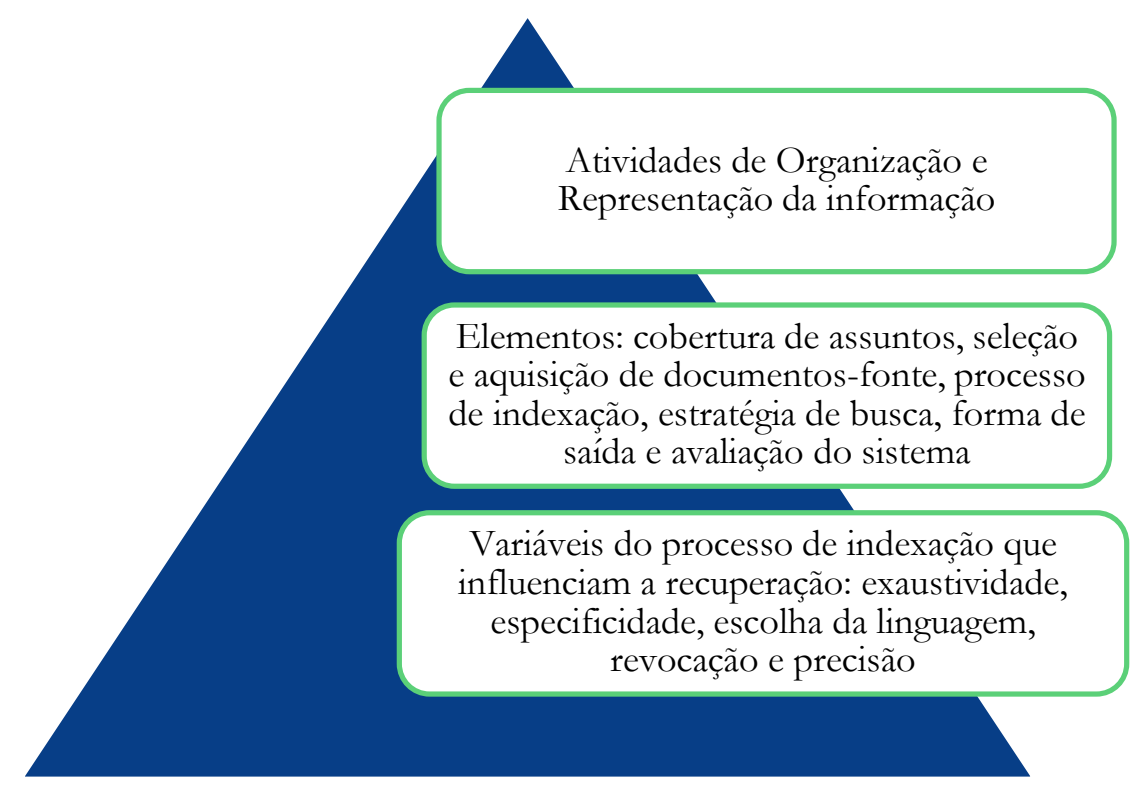

Fonte: Adaptado de Fujita, 2012, p. 23.

Os elementos elencados por Carneiro (1985) são sete: cobertura de assuntos, seleção e aquisição de documentos-fonte, processo de indexação, estratégia de busca, tempo de resposta do sistema, forma de saída e avaliação do sistema.

1. Cobertura de assuntos: assuntos cobertos pelo sistema (centrais e periféricos); atualmente deve se preocupar, também, com a conversão retrospectiva de dados e a compatibilidade de linguagem de indexação entre integrantes de um mesmo sistema cooperativo;

2. Seleção e aquisição dos documentos-fonte: extensão da cobertura do sistema em áreas de assunto e a qualidade dos documentos incluídos no sistema; levando-se em consideração a evolução tecnológica deve-se preocupar também com a procedência de páginas da internet e documentos produzidos digitalmente. 
3. Processo de indexação: desenvolve-se pela análise, síntese e representação e é influenciado pelas variáveis exaustividade, especificidade, escolha da linguagem e capacidade de revocação e precisão do sistema; em um sistema complexo ou simples é possível que o processo de indexação possa ser realizado por profissionais da informação capacitados ou, também, por pessoas autorizadas que realizam o auto arquivamento documental por meio do preenchimento de um formato de metadados; em qualquer uma dessas situações é preciso que a política de indexação esteja disponível com suas orientações e decisões em formato elucidativo para que não seja difícil realizar a indexação conforme variáveis estabelecidas;

4. Estratégia de busca: deve-se decidir entre a busca delegada ou não; atualmente é preciso tomar decisões quanto ao software e sistema de armazenagem digital que permita facilidade de acesso com segurança e integridade para todos; a delegação de busca poderá ainda ser praticada por profissionais do sistema de informação, mas os mecanismos e ferramentas de busca e acesso precisam ser amigáveis e estar disponíveis na web para qualquer usuário, seja profissional, técnico ou especialista e leigo;

5. Tempo de resposta do sistema: é um elemento que atualmente não tem necessidade de ser considerado pelo acesso simultâneo e imediato dos sistemas de busca e recuperação da informação disponíveis online na web;

6. Forma de saída: é o formato físico em que os resultados da busca são apresentados. Tem grande influência sobre a tolerância do usuário quanto à legibilidade e precisão dos resultados. Deve-se verificar qual a preferência do usuário quanto à apresentação dos resultados e para isso recomenda-se o desenvolvimento de pesquisas em design da informação para investigar a usabilidade e arquitetura da informação em ambiente digital, bem como é necessário a escolha de formatos de metadados para a inclusão dos dados que representam tanto a descrição física quanto temática (descritores da linguagem);

7. Avaliação do sistema: determinará até que ponto o sistema satisfaz as necessidades dos usuários; a avaliação é uma etapa da política que deve ser realizada antes, durante e após a implementação (Figura 4); antes, para analisar os problemas de recuperação do sistema de busca e verificar as causas; durante, para verificar ajustes na implementação da proposta elaborada para a política; após, para avaliar futuros aprimoramentos na implementação da proposta de política de indexação. 
Figura 4- Os três momentos da avaliação.

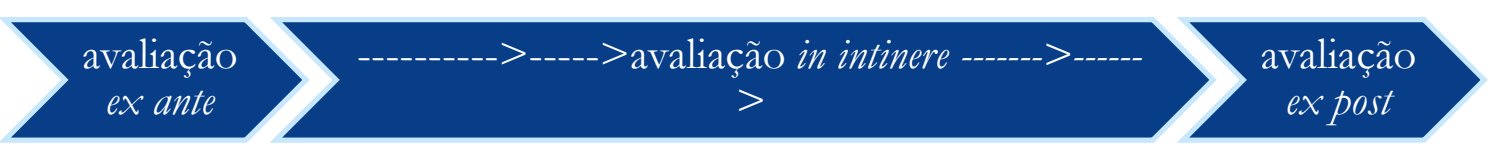

Fonte: Secchi, 2013, p. 63.

Por sua vez, o processo de indexação, como elemento essencial da política, é afetado por um conjunto de variáveis que influem na recuperação da informação. Essas variáveis, segundo Carneiro (1985), são: exaustividade, especificidade, a escolha da linguagem, revocação e precisão.

1. Nível de exaustividade: "[...] uma medida de extensão em que todos os assuntos discutidos em um certo documento são reconhecidos na operação de indexação e traduzidos na linguagem do sistema" (LANCASTER, 1968 apud CARNEIRO, 1985, p. 232);

2. Nível de especificidade: "[...] a extensão em que o sistema nos permite ser precisos ao especificarmos o assunto de um documento que estejamos processando" (FOSKET, 1973 apud CARNEIRO, 1985, p. 232);

A especificidade e exaustividade são duas variáveis que atuam durante o processo de indexação nas etapas de análise de assunto pelo indexador para identificação e seleção de conceitos e na tradução dos conceitos por termos do vocabulário controlado; a escolha de uma outra variável ou ambas influenciam de modo determinante a recuperação da informação que terá maior ou menor precisão, ou, ao contrário, maior ou menor revocação; o importante na política de indexação, além de todos os requisitos, elementos e variáveis, é que o sistema de informação possa ter o controle dos níveis de especificidade e exaustividade e isso somente se consegue com controle de vocabulário.

3. Escolha da linguagem de indexação ou do vocabulário controlado: afeta o desempenho de um sistema de recuperação de informação tanto na estratégia de busca (estabelece a precisão com que o técnico de busca pode descrever os interesses do usuário) quanto na indexação (estabelece a precisão com que o 
indexador pode descrever o assunto do documento). Portanto, a partir de estudos de recuperação da informação do sistema, deve-se optar entre linguagem natural ou vocabulário controlado; observa-se que na área de saúde a Biblioteca Virtual de Saúde (BVS) do Ministério da Saúde é referência na elaboração da Terminologia da Saúde (http://bvsms.saude.gov.br/terminologia) composta do Tesauro do Ministério da Saúde, Glossários temáticos e Siglário do Ministério da Saúde; considerando-se que o processo de indexação poderá ser realizado por profissionais da informação ou por pessoas autorizadas pelo sistema no auto arquivamento, será necessário disponibilizar o vocabulário controlado dentro do formato de metadados para que a escolha de termos de indexação seja realizada com controle de vocabulário;

4. Capacidade de revocação e precisão do sistema: exaustividade, revocação e precisão estão relacionadas. Quanto mais exaustivamente um sistema indexa seus documentos, maior será a revocação (número de documentos recuperados) na busca e, inversamente proporcional, a precisão será menor;

Os requisitos, elementos e variáveis diretamente ligados à política de indexação adotada pelo sistema influenciam o desempenho das atividades de indexação realizadas pelo sistema de informação e refletirá na recuperação da informação, sendo imprescindível a formulação de uma política de indexação que oriente todo o trabalho e a inclusão de tais itens na orientação ao indexador, seja ele profissional da informação ou não.

Considerando os elementos indicados por Carneiro (1985, p. 231) para elaboração de uma política de indexação, considera-se que o manual de indexação deve contemplar os seguintes aspectos:

- Objetivos do sistema de informação;

- Apresentação dos procedimentos de indexação para identificação e seleção de conceitos articulados com o processo de leitura documental e inclusão de um questionamento para esta finalidade, contendo exemplos em cada fase;

- Apresentação do vocabulário controlado - adotado para a representação dos conceitos selecionados, com esclarecimento e exemplos dos aspectos de estrutura, vocabulário e configuração interna para uso dos indexadores; 
- A especificação dos elementos constituintes da política de indexação do sistema: cobertura de assunto, critérios de seleção e aquisição dos documentos-fonte, nível de exaustividade e nível de especificidade.

O manual de indexação é um dos instrumentos de implementação da política de indexação, fundamental, para o registro das decisões do planejamento e acompanhamento da evolução natural das principais decisões acerca dos elementos e variáveis em função dos requisitos. Destaca-se a necessidade dos profissionais, gestores e pessoas autorizadas pelo sistema seguirem as diretrizes e orientações do manual para assegurar a uniformidade das atividades de organização e representação da informação realizadas no plano horizontal da política de indexação. A atualização do manual de indexação dependerá de reuniões regulares e periódicas de vivência, cursos de capacitação e seminários realizados pelos atores participantes da política. Para isso, sugere-se a composição de grupo que acompanhe a evolução do ciclo de política de indexação em todas as etapas.

Contudo é necessário pontuar que nenhuma política de indexação é realizada sem que haja a participação dos implementadores, os atores participantes do sistema de informação, apoiados institucionalmente para sua atuação colaborativa. 0 apoio institucional, realizado por meio de resoluções ou portarias, é o principal reconhecimento de que a política de indexação poderá ser elaborada, implementada e avaliada.

\section{CONCLUSÃO}

Diante das reflexões aqui expostas, fica evidente que a implementação de um sistema que integre política de indexação à gestão documental, em instituições de saúde, traz estabilidade e segurança aos usuários que dele se servem. Caracteriza-se como uma importante inovação, não só do ponto de vista da funcionalidade sistêmica fornecida para a rede de saúde, em plano nacional ou internacional, mas também por colaborar com o desenvolvimento científico ao proporcionar dados quantitativos e qualitativos mais precisos e de rápida recuperação aos pesquisadores da área - sejam acadêmicos, voltados para a produção científica, sejam os envolvidos no monitoramento e controle dos fatores e/ou agentes sócio ambientais que incidem na saúde da população, 
possibilitando o estabelecimento de programas de saúde preventiva e estratégias para sua efetivação, por exemplo.

Se em qualquer sistema arquivístico institucional, a implementação de um sistema, nos moldes aqui referidos, constitui questão chave para a recuperação de informações, na Saúde, então, assume posição central ao considerarmos a extensão, ramificação e complexidade de dados que alimentam o sistema. Desse modo, é fulcral o desenvolvimento de metodologias para representar a informação, dentro de uma política bem estabelecida que atenda às necessidades informacionais da organização a qual pertence. Do mesmo modo, o aperfeiçoamento de protocolos de trabalho préexistentes deve ganhar atenção, pois é capaz de propiciar facilidade e segurança em relação ao acesso de documentos e seus conteúdos.

O emprego da indexação nos procedimentos arquivísticos traz para o usuário uma vantagem extra ao permitir a recuperação de determinada informação temática em mais de um fundo, dentro ou fora da mesma instituição de custódia. À vista disso, podemos entende-la como uma interessante ferramenta de integração de dados ou informações oriundas de diferentes proveniências. Isso porque o seu objeto de interesse versa sobre conteúdos, não sobre documentos e suas dimensões, como na Arquivologia: forma, formato, materialidade, concepção intelectual, enfim, caracteres externos e internos, sempre contextualizados, conforme origem e uso.

Assim, acredita-se que a adoção de uma política de indexação de documentos de arquivo, em harmonia com a lógica e os princípios estruturadores da Arquivologia, possa trazer inúmeros benefícios aos usuários e, inclusive, revelar importantes conteúdos documentais. Consequentemente, a proposta de integração entre procedimentos, aparentemente díspares, permite além de maior compreensão sobre o contexto de produção e uso de documentos, a recuperação de informações de modo circunstanciado: um benefício aos usuários que a ela recorrem.

\section{REFERÊNCIAS}

BARBADILLO ALONSO, J. Apuntes de clasificación archivística. Legajos.

Cuadernos de Investigación Archivística y

Gestión Documental, Publicación del
Archivo Municipal de Priego de Córdoba, $\mathrm{n}$. 10, p. 27-50, 2007.

BARNAND AZAMORRUTIA, A. Guía para organización y control del expediente de 
archivo. México, DF: Archivo General de la Nación, 2002.

BRASIL. Lei 8.159, de 08 de janeiro de 1991. Dispõe sobre a política nacional de arquivos públicos e privados e dá outras providências. Diário Oficial da União, Brasília, 09 jan. 1991.

BRASIL. Ministério da Justiça. Conselho Nacional de Arquivos. Resolução n222 de 30 de junho de 2005. Dispõe sobre as diretrizes para a avaliação de documentos em instituições de saúde. Diário Oficial da União, Brasília, 4 jul. 2005, Seção 1, p. 5. Disponível em: <https://bit.ly/2TGkqiD>. Acesso em: 9 set. 2018.

BRASIL. Ministério da Saúde. SecretariaExecutiva. Departamento de Monitoramento e Avaliação do SUS. Política Nacional de Informação e Informática em Saúde. Brasília: Ministério da Saúde, 2016. 56 p. Disponível em: <https://bit.ly/2A7dKAJ>. Acesso em: 18 jun. 2018.

BRASIL. Presidência da República. Casa Civil. Arquivo Nacional. Conselho Nacional de Arquivos. Portaria no 93 de 18 de novembro de 2010. Diário Oficial da União, Brasília, 22 de novembro de 2010, Seção 1, fl.1. Disponível em: <https://bit.ly/2P1Gjp9>. Acesso em: 19 jul. 2018.

BRASIL. Presidência da República. Casa Civil. Subchefia para Assuntos Jurídicos. Lei no 12.527, de 18 de novembro de 2011. Regula o acesso à informações previstos no inciso XXXIII do Art. 5ํㅡㄹ no inciso II do $\S 3^{\circ}$ do Art. 37 e no $\S 2^{\circ}$ do art. 216 da Constituição Federal: altera a Lei 8.11211 dezembro de 1990; revoga a Lei 11.111, de 5 de maio de 2005, e dispositivos da Lei no 8.159, de 8 de janeiro de 1991; e dá outras providências, Brasília, 2011. Disponível em: $<$ https://bit.ly/1eKDwfY>. Acesso em: 4 ago.2018.

CARNEIRO, M. V. Diretrizes para uma política de indexação. R. Esc. Bibliotecon. UFMG, Belo Horizonte, v. 14, n. 2, p. 221-241, 1985.

CONSELHO FEDERAL DE MEDICINA. Resolução CFM no 1821. Aprova as normas técnicas concernentes à digitalização e uso dos sistemas informatizados para a guarda e manuseio dos documentos dos prontuários dos pacientes, autorizando a eliminação do papel e a troca da informação identificada em saúde. Diário Oficial da União, Brasília, 23 nov. 2007, Seção 1, p. 252. Disponível em: <https://bit.ly/1Xocuzn>. Acesso em: 8 ago. 2018.

CONSELHO NACIONAL DE ARQUIVOS Conarq (Brasil). Câmara Técnica de Documentos Eletrônicos. e-ARQ Brasil: Modelo de Requisitos para Sistemas Informatizados de Gestão Arquivística de Documentos / Câmara Técnica de Documentos Eletrônicos. 1.1. versão. - Rio de Janeiro: Arquivo Nacional, 2011.

CRUZ MUNDET, J. R. La gestión de documentos en las organizaciones. Editorial: Ediciones Pirámide, Madrid, 2008.

FOSKET, A. C. A abordagem temática da informação. São Paulo: Polígono, 1973.

FUJITA, M. S. L. A política de indexação para representação e recuperação da informação. In: GIL LEIVA, I.; FUJITA, M. S. L. Política de indexação. São Paulo: Cultura Acadêmica, 2012. p. 17-28.

FUJITA, M. S. L. Política de indexação para bibliotecas: estudo de elaboração, implantação e avaliação com pesquisa-ação integral. In: CONGRESO ISKO, 8., 2017, Espana; CONGRESO ISKO, 3., 2017, EspanaPortugal, Coimbra. Tendências Atuais e Perspectivas Futuras em Organização do Conhecimento: atas do CONGRESSO ISKO, 3., 2017. Coimbra: Universidade de Coimbra, Centro de Estudos Interdisciplinares do Século XX - CEIS20, 2017. v. 1. p. 213-224. Disponível em: <https://bit.ly/2THWxHu>. Acesso em: 29 jun. 2018.

FUJITA, M. S. L.; GIL LEIVA, I. A avaliação da indexação por meio da recuperação da informação. Ciência da Informação, Brasília, v. 43, n. 1, p. 50-66, 2014.

HEREDIA HERRERA. A. ¿Qué es un archivo? Gijón Asturias: Ediciones Trea, 2007. 
JAKOBSON, R. Linguística e comunicação. São Paulo: Cultrix, 1974.

LANCASTER, F. W. Information retrieval systems: characteristics, testing and evaluation. New York: John Wiley \& Sons, 1968.

LLANES PADRÓN, D., FUJITA, M. S. L. La representación de documentos y autoridades archivísticas: una mirada desde la perspectiva de la normalización. Perspectivas em Ciência da Informação, Belo Horizonte, v. 22, n. 2, p. 211-231, abr./jun. 2017. Disponível em: <https://bit.ly/20YNr5x>. Acesso em: 16 jul. 2018.

MARTÍN-POZUELO CAMPILLOS, M. P. La construcción teórica en archivística: el principio de procedencia. Madrid: Universidad Carlos III/Boletín Oficial del Estado, 1996.

MELLO E SILVA, M. C. S. (Org.) Glossário de espécie e tipos documentais em arquivos de laboratórios. Rio de Janeiro: Museu de Astronomia e Ciências Afins, 2014.

MORIN, A. Pesquisa-ação integral e sistêmica: uma antropedagogia renovada. Trad. de Michel Thiollent. Rio de Janeiro: DP\&A, 2004. 232 p.

MOTA, F. R. L. Padronização da informação em saúde. In: PINTO, V. B., CAMPOS, H. H. (Org.) Diálogos paradigmáticos sobre informação para a área da saúde. Fortaleza: Edições UFC, 2013. p. 207-44.

PINTO, V. B., SILVA NETO, C. Representação indexal como mediação informacional em prontuário do paciente. In: PINTO, V. B.; CAMPOS, H. H. (Org.) Diálogos paradigmáticos sobre informação para a área da saúde. Fortaleza: Edições UFC, 2013. p. $143-70$.
SANTOS, P. R. E. Arquivos de instituições de saúde: história e políticas públicas. In: BENTES PINTO, V.; SOARES, M. E. (Org.) Informação para a área de saúde: prontuário do paciente, ontologia de imagem, terminologia, legislação e gerenciamento eletrônico de documentos. Fortaleza: Edições UFC, 2010. p. 101-114.

SECCHI, L. Políticas públicas: conceitos, esquemas de análise, casos práticos. 2. ed. São Paulo: Cengage Learning, 2013, 168 p.

SIGMOND, J. P. Form, Function and Archival Value. Archivaria, [S.l.], jan. 1991. Available at:<https://bit.ly/2r4P3kw>. Acessado em: 19 jul. 2018.

\section{THIOLLENT, M. Metodologia pesquisa} ação. 8. ed. São Paulo: Cortez, 1998. 108 p.

TROITIÑNO, S. Apenas um arquivista: a formação do arquivo de Lívio Xavier In: TROITIÑO, S.; LUCA, T. R. (Org.). Sobre a arte de guardar Reflexões a respeito do acervo de Lívio Xavier. 1. ed. São Paulo: Cultura Acadêmica, 2017. v.1, p. 67-89.

TROITIÑNO, S.; FUJITA, M. S. L.; NEVES, D. A. B. Indexing in records management. In: INTERNATIONAL SOCIETY FOR KNOWLEDGE ORGANIZATION (ISKO), Brazil- São Paulo, UNESP University. (Org.). Knowledge Organization for a Sustainable World:Challenges and perspectives for Cultural, Scientific, and Technological Sharing in a Connected Society. Proceedings of the Fourteenth International ISKO Conference 27-29 Set. 2016, Rio de Janeiro, Brazil. 1ed. Würzburg: ERGON VERLAG, 2016. v. 1, p. 234-242.

\section{NOTAS}

${ }^{\text {i } A ~ r e v i s a ̃ o ~ o r t o g r a ́ f i c a, ~ g r a m a t i c a l ~ e ~ e m ~ L i ́ n g u a ~ P o r t u g u e s a ~ e ́ ~ d e ~ r e s p o n s a b i l i d a d e ~ d a s ~ a u t o r a s . ~}$ 